\title{
SINDROMUL SMITH-LEMLI-OPITZ. PREZENTARE DE CAZ
}

\author{
Sorin Ioan Iurian ${ }^{1,2}$, Livia Ognean ${ }^{3}$, Han Brunner ${ }^{4}$, Leo Kluijtmans ${ }^{5}$, Petr Jira ${ }^{6}$, \\ Dana Fîntînă ${ }^{2}$, Bogdan Ionuț Mehedințu ${ }^{2}$ \\ ${ }^{1}$ Universitatea ,Lucian Blaga“, Sibiu \\ ${ }^{2}$ Spitalul Clinic de Pediatrie, Sibiu \\ ${ }^{3}$ Clinica Neonatologie, Spitalul Clinic de Urgență, Sibiu \\ ${ }^{4}$ Departamentul Genetică Medicală, Universitatea Radboud, Nijmegen, Olanda \\ ${ }^{5}$ Laboratorul de Medicină Translațională, Nijmegen, Olanda \\ ${ }^{6}$ Spitalul Jreoen Bosch, Departamentul Pediatrie, Olanda
}

\begin{abstract}
Sindromul Smith-Lemli-Opitz (SSLO) reprezintă o afecțiune cu transmitere autozomal-recesivă caracterizată prin multiple anomalii şi care se datorează anomaliilor în sinteza colesterolului. Autorii prezintă particularitățile diagnostice şi terapeutice la un sugar cu ambiguitate genitală.
\end{abstract}

Cuvinte cheie: sindromul Smith-Lemli-Opitz, sugar, hipocolesterolemie

\section{INTRODUCERE}

Sindromul Smith-Lemli-Opitz (SSLO) este o afecțiune cu transmitere autozomal-recesivă caracterizată prin multiple malformații secundare anomaliilor în sinteza colesterolului. Sindromul a fost descris iniţial de Smith, Lemli şi Opitz, în 1964 (1).

\section{Etiologie}

Cauza bolii a rămas necunoscută până în anul 1993 când Irons şi colaboratorii (2) au remarcat, la cazurile cu SSLO, nivelul plasmatic redus de colesterol asociat cu valoarea crescută a precursorilor colesterolului: 7-dehidrocolesterol (7DHC), 8-dehidrocolesterol (8DHC). Sindromul este cauzat de deficitul enzimei delta-7 dehidro-colesterol reductază (7DHC reductază), ce transformă 7DHC în colesterol.

\section{Fiziopatologie}

În consecință, se acumulează precursorii colesterolului, iar colesterolemia scade. Colesterolul intervine în sinteza membranelor celulare, a hormonilor steroidieni (Fig. 1), a acizilor biliari şi mielinei. De asemenea, există deficit de cooperare dintre colesterol şi proteina embrionică „Shh“ (în zilele 0-7 de gestație), cu are rol în dezvoltarea structurilor feței, cordului, membrelor şi creierului.

\section{Epidemiologie}

Prevalența bolii a fost estimată la 1:20.000 1:60.000 naşteri, la rasa albă. Raportul pe sexe este de $1: 1$.

\section{Mortalitate şi morbiditate}

Rata avorturilor spontane la fetuşii cu SSLO este crescută. În prima săptămână de viață, decesul 


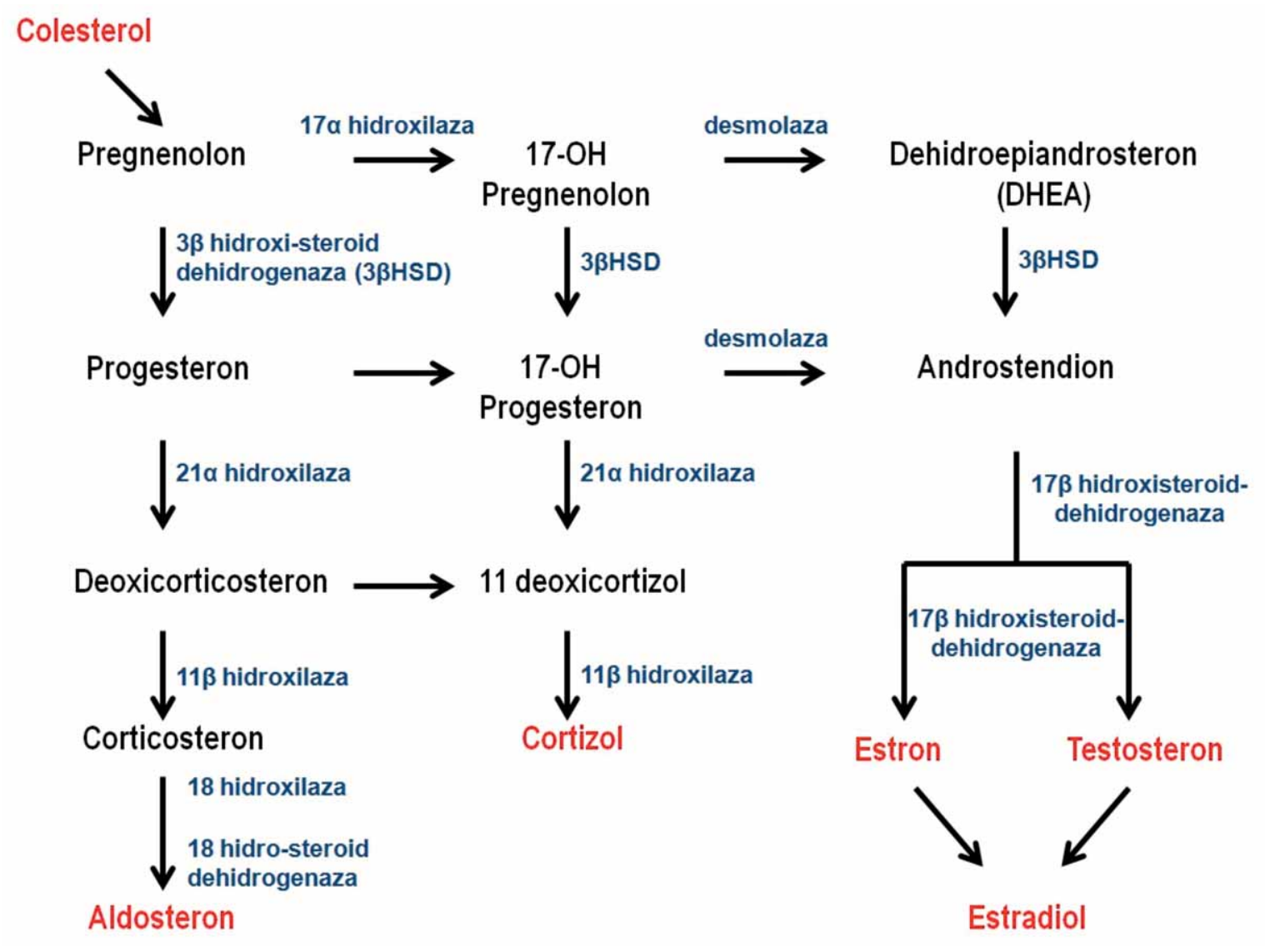

FIGURA 1. Căile enzimatice de sinteză a aldosteronului, cortizolului şi androgenilor

este relativ frecvent şi se datorează insuficienței multiple de organe. Colesterolemia sub $20 \mathrm{mg} \%$ constituie factor de prognostic rezervat. În SSLO au mai fost descrise hepatopatia (3), hipoacuzia, tulburările de vedere (cataractă) (4) şi retardul de creştere şi dezvoltare. Clinic, la nou-născuți se remarcă retardul de creştere intrauterin, hipotonia generalizată severă şi plânsul particular (strident).

Studiile anterior efectuate (Kelley şi Hennekam, 2000), analizând 164 de cazuri confirmate biochimic, au demonstrat în SSLO următoarele anomalii: retard mental (95\% dintre cazuri), retard de creștere post-partum $(82 \%)$, microcefalie $(84 \%)$, anomalii structurale cerebrale (37\%), ptoză palpebrală $(70 \%)$, cataractă $(22 \%)$, nări anteversate $(78 \%)$; palatoschizis $(47 \%)$, anomalii cardiace $(54 \%)$, lobulare pulmonară anormală $(45 \%)$, stenoză pilorică (14\%), aganglionoză colonică (16\%), anomalii renale $(43 \%)$, anomalii genitale $(65 \%)$, sindactilie parţială degete 2 şi 3 picior bilateral $(97 \%)$ şi polidactilie postaxială ( $48 \%$ dintre cazuri). Fenotipul este variabil, de la forme uşoare la forme severe de boală, cu insuficiență multiplă de organe şi deces.

\section{Diagnostic}

Prenatal, suspiciunea de boală se stabileşte utilizând ultrasonografia fetală ce relevă anomalii sugestive, justificându-se testarea nivelului de 7DHC în lichidul amniotic sau evaluarea activității enzimei 7DHC reductază în celulele vilozităților coriale. Testarea genetică reprezintă o altă opțiune. Triplul sau cvadruplul test matern sugestiv pentru sindromul Down dar cu cariotip normal poate constitui un marker diagnostic pentru SSLO. Shackleton (5) a demonstrat prezența estriolului în urina mamei însărcinate cu făt cu SSLO, evaluarea putând fi utilizată în screeningul non-invaziv prenatal.

Postnatal, diagnosticul se confirmă biochimic şi/ sau genetic. Biochimic, SSLO este definit de nivelul plasmatic redus de colesterol asociat cu valoarea mult crescută a 7DHC. Evaluarea doar a colesterolemiei nu este recomandată, important în diagnostic fiind calcularea raportului dintre precursorii colesterolului (7DHC şi 8DHC) pe de o parte şi colesterolemie pe de altă parte. Sudiile imagistice (IRM/ CT cerebral, ultrasonografia cardiacă/abdominală etc.) decelează anomaliile descrise în SSLO. 
Biopsia rectală confirmă boala Hirschsprung, iar potențialele evocate auditive identifică hipoacuzia la sugari.

\section{Tratament}

Până în prezent niciun tratament nu şi-a dovedit eficiența (6). Menționăm în continuare câteva din opțiunile terapeutice:

- aportul oral de colesterol poate creşte colesterolemia. Prin feed-back negativ, colesterolul inhibă hidroxi-metil-glutaril-CoA reductază (HMGCoA reductază), reducând precursorii colesterolului; doza orală recomandată este de $100 \mathrm{mg} / \mathrm{kg}$. corp/zi şi poate fi asigurată prin consum de gălbenuş de ou, smântână sau unt; studiile au confirmat absorbția superioară a colesterolului din gălbenuşul de ou raportat la microcristale de colesterol (7); administrat oral, colesterolul nu penetrează membrana hemato-encefalică, astfel că tulburările de comportament (automutilare, autism etc.) nu se ameliorează $(8,9)$;

- suplimentarea orală cu acizi biliari (ex: acid urso-dezoxicolic);

- statinele (Simvastatin) determină reducerea raportului $7 \mathrm{DHC}+8 \mathrm{DHC} /$ colesterol prin două mecanisme:

1. blocarea enzimei HMG-CoA reductază scade nivelul precursorilor colesterolului;

2. activarea enzimei 7DHC reductază (,up-regulation") conduce la ameliorarea colesterolemiei (10).
Tratamentul chirurgical presupune corecția polidactiliei, montarea de gastrostomă sau terapia chirurgicală a bolii Hirschsprung.

\section{PREZENTARE DE CAZ}

Sugarul T.B., în vârstă de 5 săptămâni, se internează prin transfer din secția neonatologie pentru evaluare suplimentară în contextul ambiguității genitale, a sindromului plurimalformativ şi dismorfismului cranio-facial.

Antecedente heredo-colaterale: părinți - sănătoşi, fără relații de consangvinitate; mama minoră, IIG IP (prima sarcină - avort spontan). Din antecedentele obstetricale: naştere la vârsta gestatională 9 luni prin operație cezariană la 19 ore de la ruperea spontană a membranelor amniotice, lichid amniotic meconial; greutate $3.010 \mathrm{~g}$; APGAR $=7 / 1 \mathrm{~min}$; reflexul de supt incorect a determinat iniţierea alimentației pe sonda nazo-gastrică.

Investigațiile efectuate în clinica neonatologie: poliglobulie, hiponatremie şi hiperpotasemie (sindrom de pierdere de sare?), hipocolesterolemie (37 $\mathrm{mg} \%$ ). Cariotiparea a confirmat sexul genetic masculin $(46, \mathrm{XY})$. Imagistic: ultrasonografia a decelat hipoplazie corp calos, glande suprarenale cu structură dezorganizată, iar la nivel scrotal a evidenţiat testicule de dimensiuni normale.

Examenul clinic la data transferului: stare generală mediocră; greutate $3.000 \mathrm{~g}$, perimetrul cranian $=33 \mathrm{~cm}$ (la naştere $32 \mathrm{~cm}$ ); tegumente palide; plică

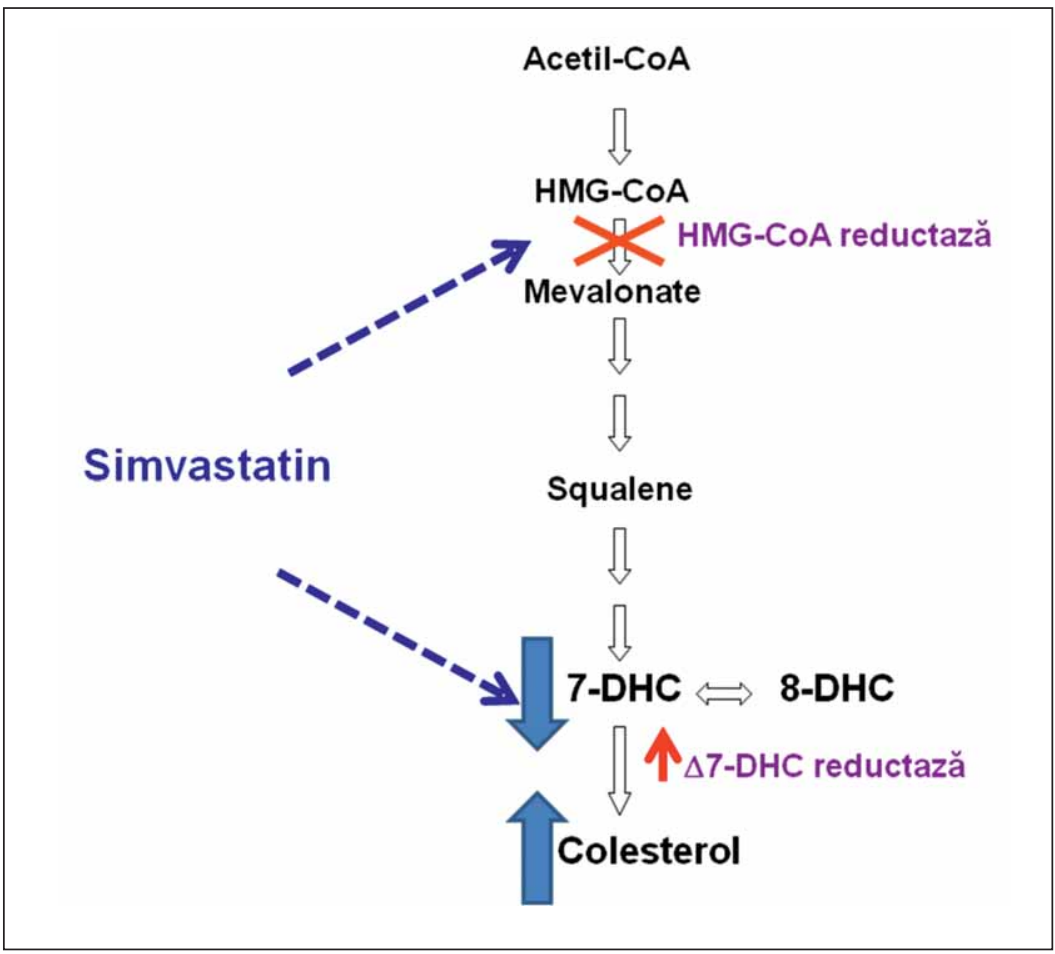

FIGURA 2. Simvastatin. Mod de acțiune (după Petr Jira) 
simiană mână bilateral; țesut subcutanat slab reprezentat global, hipotonie generalizată, dismorfism cranio-facial (fante palpebrale cu dispoziție antimongoloidă, ptoză palpebrală, epicantus, nări anteversate, micrognație; urechi rotate posterior), sindactilie degete $2 / 3$ picior bilateral, ambiguitate genitală (micropenis, scrot bifid, hipospadias penian/ scrotal).

Investigații: leucocite $22.700 / \mathrm{mm}^{3}, \mathrm{Hgb}=10,54$ $\mathrm{g} \%$; Tr. $=243.000 / \mathrm{mm}^{3}$; bilanț hepato-renal normal; glicemie normală; ionograma sangvină a relevat tendinţă la hiponatremie şi hiperpotasemie, cu normalizare în evoluție; colesterol seric $=27 \mathrm{mg} \%$.

Evaluare endocrinologică: 17 hidroxi-progesteron $=7,51 \mathrm{ng} / \mathrm{ml}$ (normal 3,6-13,7); cortizolemie $=16,3 \mu \mathrm{g} / \mathrm{dl}$ (normal 15-25); Dehidro-epiandrosteron $($ DHEA $)=2,37 \mathrm{ng} / \mathrm{ml}$ (normal $0,26-3,85)$; testosteron seric $=0,16 \mathrm{ng} / \mathrm{ml}$ (normal 1,42-9,21); aldosteron seric $=28,4 \mathrm{ng} / \mathrm{dl}$ (normal 1,76-23,2).

Ecografia abdominală a evidențiat duplicația renală stângă cu hidronefroză grad I, iar testarea funcției auditive a confirmat la caz hipoacuzia unilaterală stângă.

Diagnostic diferențial, în contextul ambiguității genitale, a inclus:

- subvirilizarea masculină datorată tulburărilor de diferențiere testiculară şi a tulburărilor în acțiunea androgenilor (insensibilitate la androgeni, deficit 5- $\alpha$ reductază). Ultimele două entități sunt puțin probabile (vezi testosteronemia redusă);

- deficitul de 21-hidroxilază cu hipervirilizare se elimină pe baza valorilor normale ale 17$\mathrm{OH}$ progesteronului/DHEA şi a cariotipului 46, XY;

- tulburările de diferențiere a cromozomului sexual (sdr. Turner şi Klinefelter, disgenezie gonadală mixtă, hermafroditism adevărat) se exclud (cariotip la caz 46, XY);

- sindroame cu ambiguitate genitală (DenisDrash, WAGR, Goldenhar, Robinow şi SmithLemli-Opitz) au fost, de asemenea, analizate.

\section{Diagnostic pozitiv}

Sindromul plurimalformativ (dismorfism craniofacial, anomalii genito-urinare şi cerebrale) corelat cu hipocolesterolemia, a orientat diagnosticul către
SSLO, justificându-se evaluarea profilului sterolic care a arătat creşterea $7 \mathrm{DHC}(113 \mu \mathrm{mol} / 1$, normal < $5 \mu \mathrm{mol} / 1)$ şi $8 \mathrm{DHC}(83 \mu \mathrm{mol} / \mathrm{l}$, normal $<1 \mu \mathrm{mol} / \mathrm{l})$ şi hipocolesterolemia $(614 \mu \mathrm{mol} / 1$, normal 2.000 5.200). Profilul sterolic a confirmat din punct de vedere biochimic SSLO, testarea genetică nefiind necesară. Se consideră la caz tipul II de boală.

Obiectivele terapeutice au urmărit:

- suport nutriţional cu administrarea meselor pe sonda nazo-gastrică; s-a utilizat şi soluţie nutritivă hipercalorică; s-a iniţiat dieta cu colesterol p.o. (1 gălbenuş ou /zi);

- reducerea raportului precursori/colesterol utilizând Simvastatin 1 mg/kg./zi p.o.

\section{Evoluție}

Clinic, sugarul a prezentat sepsis în ziua a 9-a de spitalizare, justificându-se antibioticoterapia empirică cu spectru larg, cu evoluție favorabilă. Se remarcă persistența microcefaliei şi a retardului ponderal (greutate $3.200 \mathrm{~g}$ la 3 luni).

Biologic, se remarcă ameliorarea hipocolesterolemiei (creştere de la 27 mg\% la 39 mg\%), dar fără îmbunătățire semnificativă pe plan neurologic.

\section{CONCLUZII}

1. Autorii prezintă cazul unui sugar cu sindrom plurimalformativ şi hipocolesterolemie severă, acest ultim detaliu orientând demersurile diagnostice către SSLO;

2. Se remarcă profilul endocrinologic particular (testosteronemia redusă cu valorile normale cortizol şi aldosteron, deşi colesterolul reprezintă substratul acestor hormoni). Substituția hormonală (testosteron) nu se impune. De remarcat sindromul tranzitor de pierdere de sare;

3. Întrucât prima sarcină s-a finalizat cu avort trimestrul I, considerăm ca probabilă afectarea embrionului de SSLO;

4. În evoluție, cazul necesită monitorizarea terapiei evaluând trimestrial profilul sterolic, reconstrucția organelor genitale externe corespunzător fenotipului masculin, protezarea auditivă şi suportul psihologic. Astfel, terapia este multidisciplinară (pediatru, psiholog, chirurg etc). 